\title{
Negotiating narrative
}

\section{Dialogic dynamics of known, unknown and believed in Harry Potter and the Deathly Hallows}

\author{
Gill Philip, Ramona Bongelli, Carla Canestrari, Ilaria Riccioni, \\ and Andrzej Zuczkowski
}

University of Macerata, Italy

\begin{abstract}
Within the framework of KUB Theory (Bongelli and Zuczkowski 2008, Zuczkowski et al. 2011), information communicated verbally can ultimately be reduced to one of three categories: what the speaker knows (Known), what the speaker does not know (Unknown) and what the speaker believes (Believed). Dialogic communication can be considered as an exchange of information originating in one of these categories and directed towards another. The present study investigates the interaction of Known, Unknown and Believed information in the dialogues found in Chapter 10 of Harry Potter and the Deathly Hallows. It demonstrates how these three categories of information can contribute to a reading of the plot and its progression, and also how aspects of the protagonists' characters emerge through the language they use in their dialogic communication.
\end{abstract}

Keywords: characterisation, dialogue, epistemicity, evidentiality, Harry Potter, known, unknown, believed

\section{Harry Potter and the world of academia}

The Harry Potter books are no strangers to academic analysis. In spite of the fact that many literary scholars and critics were quick to write them off as derivative (Hensher 2000, Byatt 2003), and not the stuff that 'great' or 'classic' literature is made of (Safire 2000, Pennington 2002, Thomas 2007; ${ }^{1}$ but see also Billone 2004), they have sparked the interest of many researchers across several disciplines, and that interest has well outlived the initial criticism. Studies abound in a range of different areas of scholarship, from literature to sociology, psychoanalysis to religious studies (to get an idea of the quantity and range of studies, see Rémi 2012). 
To date, there are relatively few published works which deal with all seven books viewed as a series. Of course this is partly a consequence of publication schedules: it is inevitable that recent work is still in preparation or in press, and hence effectively invisible. But it is also true that there was a flurry of interest in Books 1-4, which has tailed off markedly in the interim. Why this should be so can be attributed to some extent to the nature of the research that has dominated 'Potter studies', which is largely sociological in outlook. Indeed 'Pottermania', the sociological and cultural phenomenon which has emerged as a result of the books' enormous popularity, is in itself an area of academic research. Here, the focus of attention shifts from the books themselves to the fans and the various spin-off phenomena which have appeared, most notably the extensive fan fiction (see for instance Green and Guinery 2004, Glaubmann [ed.] forthcoming).

Leaving aside such areas of research which concentrate on the spill-over of the Harry Potter world into the world at large, we are left with those works which actually investigate the content of the books. Early studies - in particular those dealing with the first book - were fascinated by the names of Rowling's characters and magical-world terms, the connotative meanings that these evoked, and the ways in which these were translated out of the original (British) English text. ${ }^{2}$ It is fair to say that the majority of linguistics studies have focused on these aspects of Harry Potter, and that little need seems to have been felt to replicate or widen existing studies to take into account the complete seven-book series.

Another area of study which has borne fruit is the application of Gender Studies methodology to the novels (e.g. Cherland 2008, Doughty 2002, Dresang 2002, Goatley 2004 inter alia, Heilman and Donaldson 2009); and a perplexing array of research has been dedicated to the sexual orientation, attested or otherwise, of the characters; in other words, queer theory (e.g. Bronski 2003, Nylund 2007, Kidd 2008) has found a considerable amount to say about a topic whose relation to the books and the plot of the series is fairly tangential. And here again, analysis of Rowling's texts has been somewhat limited; at least as much attention - if not more - is paid to interview-based material, in which the author expounds upon her characters, as it is to the actual books in which the characters appear (cf. Tosenberger 2008a, 2008b).

If we limit our scope, then, to analyses of the text and plot, the seemingly endless Potter studies bibliography shortens considerably. As already mentioned, linguistic-literary analyses have investigated gender representation, both as far as individual books are concerned and with reference to character development over the series. Related to this are studies of the character roles - not their gender roles, but rather what the function of each character is within each book and within the series as a whole. Why, for example, does the hero, Harry, require two best friends rather than only one, ${ }^{3}$ and what are they for as far as the narrative is concerned? 
Clearly, fictional characters are related to plot - their role being to contribute to the success of the Hero's quest - and yet little has been published about the plot as such other than to note that the books follow the same narrative pattern and, with reference to the unfinished series, how the story would conclude (Granger 2007). ${ }^{4}$

The present study, in fact, is an off-shoot of an 'anomaly' in the Potter studies canon. It is located within an investigation into plot and character development over the seven-book series. Unlike more literary-orientated studies, the primary aim of the parent project is to pinpoint specific literary effects in the texts - from twists in the tale to revelations about characters' personalities and affiliations from a purely linguistic standpoint. It uses corpus linguistics tools and methods to analyse keywords and collocational patternings in context, and chronologically, to investigate how patterns emerge, coalesce and fracture over the course of the books (Philip 2010, 2011). The present study, however, is not a corpus-linguistics study as such, although it makes some use of corpus tools. It is instead an investigation into evidentiality, epistemicity, information and knowledge in (a small part of) Harry Potter; to our knowledge, it is the only such study in existence at present.

\section{The theory of the known, the unknown, and the believed}

The Theory of the Known, the Unknown, and the Believed (KUB Theory) emerged from studies of non-dialogical written texts in Italian (Bongelli, Zuczkowski 2008, Zuczkowski et al. 2011) and in English (Bongelli et al. 2012), and was subsequently tested on a corpus of Italian political speeches and dialogues (Bongelli et al. forthcoming, Riccioni et al. forthcoming). KUB Theory is located within the broader field of investigations into evidentiality, epistemicity, and their relationship. This area of study has attracted a great deal of interest over the past three decades or so, inevitably resulting in a multitude of terms and conflicting definitions (see Dendale and Tasmowski 2001). In this section we provide an overview of the field (2.1) and introduce the central elements of KUB Theory (2.2).

\subsection{Evidentiality and epistemicity}

With the term evidentiality, scholars generally refer to the coding of sources of information and modes of knowing (see Chafe 1986, Cornillie 2007), i.e. the linguistic markers that reveal how speakers/writers gain access to the piece of information they communicate (Willett, 1988).

In terms of the mental processes involved, clearly of interest to communication psychology, access to information can occur through perception (the five senses, as well as proprioception), and cognition (thought, memory, imagination 
etc.). For this reason, not only are verbal expressions such as I see, I remember, I know... evidential markers, but so too are I think, I believe, I imagine, I suppose..., because opinions, beliefs, imagined scenarios, suppositions etc. are also considered to be modes of knowing and in this respect are sources of information.

In addition to the actual information communicated, and activated simultaneously in the perception / cognition process, are the notions of time and space. The place and time when communication occurs (Here and Now) determines whether that information is Known, Unknown, or Believed at the time of speaking. It is important to stress that in this sense the KUB status at the time of speaking may well differ from the KUB status at another time; for instance, if we are reporting a past state or event, it is not the status of the information at the time when it occurred that is to be considered, but rather its status at the time when we report it. So I didn't see (= There and Then) communicates known information at the time of speaking (Here and Now I remember that There and Then I didn't see). In other words, from a psychological point of view, the source of information always reverts to the speaker/ writer in the place and time when he or she is communicating information, and not in the place or time referred to in the information conveyed (cf. Petöfi 1973, 2004).

An equally wide range of studies has also been conducted into epistemicity (certainty and uncertainty) and here again, many different definitions and viewpoints have arisen. These include such notions as the speaker/writer's attitude regarding the reliability of the information (see for example, Fitneva 2001, Dendale, Tasmowski 2001, González 2005), the speaker/writer's judgment of the likelihood of the proposition (see for example, Nuyts 2001, Cornillie 2007), and, additionally, the speaker/writer's commitment to the truth of the message (see e.g., De Haan 1999, Sanders, Spooren 1996). All these definitions can be reconceptualized in terms of the speaker/writer's view of 'certainty' and 'uncertainty' regarding the information that is being communicated.

Given the range of applications of the terms evidentiality and epistemicity, it should hardly come as a surprise that the relationship between them has also been the object of much debate. The literature of the field identifies three broad types of relationship: disjunction, inclusion, and overlap (Dendale and Tasmowski 2001, González 2005, Cornillie 2007, Boye 2010). In the first of these, disjunction (De Haan 1999, Aikhenvald 2003, 2004), evidentiality and epistemicity are considered to be as distinct categories/concepts. Inclusion (Givón 1982, Chafe 1986, Palmer 1986, Willett 1988, Papafragou 2000, Mushin 2001, Ifantidou 2001), on the other hand, views evidentiality and epistemicity as categories/concepts falling within the scope of each other. Indeed, for some authors evidentiality is included in epistemicity, while for others it is epistemicity which is included in evidentiality. Finally, in the third type of relationship between evidentiality and epistemicity, the two concepts overlap (Van Der Auwera and Plungian 1998, Plungian 2001), and thus partially intersect. 


\subsection{Knowledge and certainty}

Having investigated evidentiality, epistemicity, and their relationship in a substantial number of texts in both Italian and English, the originators of KUB theory noted two main findings. The first of these is that although there is a bewildering range of evidential and epistemic markers available to speakers/writers, they can all ultimately be reduced to three information categories, i.e. I know, I do not know, I do not know whether (= I believe), as illustrated in Figure 1. These correspond to the three basic evidential and epistemic 'territories of information' (after Kamio 1994, 1997) of the Known, the Unknown, and the Believed.

The Known comprises all information that speakers/writers say they 'know' in the broadest sense (i.e. that they perceive, remember, etc.), e.g. Alex is on the beach, or I see that Alex is on the beach. The Unknown, in contrast, is the information that speakers/writers say they do not know at all, e.g., I don't know where Alex is, or Where is Alex? The Believed is an intermediate category, which groups together everything which does not constitute knowledge per se, such as beliefs, opinions, impressions, suppositions, conjectures, and so on; i.e. all information that speakers/writers say they do not know if or do not know whether, e.g. I do not know if Alex is on the beach, or I think that Alex in on the beach (=I think he may be on the beach, but I don't know for certain). It is important to note the difference between not knowing if/whether (Believed) and not knowing (Unknown): information which is communicated as Unknown involves absence of knowledge (I don't know at all, I have no idea, I don't have the faintest idea) rather than beliefs or suppositions which are unconfirmed or uncertain.

Stemming from this distinction between Unknown and Believed is the relationship between evidentiality (source of information) and epistemicity (certainty/ uncertainty). When information is communicated as Known it is simultaneously communicated as being certain, and vice versa. In saying, e.g. I see that Alex is on the beach, the information source $I$ see is the evidential marker, referring as it does to one of the five senses. Yet even in the absence of an explicit epistemic marker (e.g., I am sure), certainty is simultaneously communicated through the evidential (perceptual) verb see. In the same way, information communicated as Believed is simultaneously communicated as uncertain (and vice versa). Thus in saying I think that Alex is on the beach, the evidential (cognitive) marker I think communicates uncertainty, because the speaker is indicating that he or she knows that the situation is possible and/or likely, but does not know whether it is actually true. Finally, information conveyed as Unknown is neither certain nor uncertain: the Unknown is marked by absence of information and as a result cannot communicate either certainty or uncertainty, both of which require information to be present. 


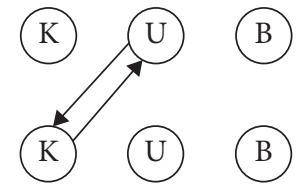

S1: Where is Alex? S1: Alex is on the beach

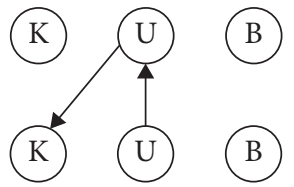

S1: Where is Alex?

S1: I don't know where Alex is

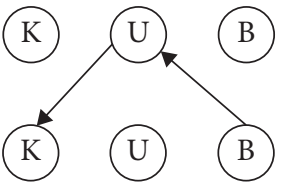

S1: Where is Alex?

S1: I think that Alex is on the beach

Figure 1. Three examples of communicative exchanges according to KUB theory. The circles $\mathrm{K}, \mathrm{U}, \mathrm{B}$ represent the three territories of information; the starting point of the arrow indicates the territory from which the communicated information comes; the arrowhead indicates the territory towards which the information is addressed.

According to KUB Theory, dialogic communication involves an exchange of information; this information originates in one of the three evidential and epistemic territories and is directed at another. Figure 1 illustrates this exchange based on the simple utterance Where is Alex? In the dialogue on the left, Speaker 1's utterance can be paraphrased as I don't know $\mathrm{p}(\mathrm{p}=$ Alex's location) and I expect you (= S2) to know $\mathrm{p}$ and to tell me. The expression I don't know $\mathrm{p}$ means that S1's question originates in his/her the territory of the Unknown, while the implication I expect you (=S2) to know $\mathrm{p}$ and to tell me indicates that S1's question is addressed to S2's territory of the Known.

In the dialogue on the left, S2 answers Alex is on the beach. This information comes from S2's territory of the Known and is addressed to S1's territory of the Unknown, as represented by the circles and arrows. Yet if, as in the central dialogue, S2 answers I don't know, this information comes from S2's territory of the Unknown and is addressed to S1's world of the Unknown. Finally, if S2 answers I think that Alex is on the beach, as in the right-hand dialogue, this information comes from S2's territory of the Believed and is addressed to S1's territory of the Unknown. Thus we can see that whatever S2 says, the information must originate in one of the three territories. It cannot not come one of the three: KUB Theory permits no further option.

\subsection{Markers of the known, the unknown, and the believed}

Known, Unknown and Believed information is signalled in text by a wide range of lexical and morphosyntactic markers. In this subsection we provide an outline of the main types of lexical and morphosyntactic markers of the Known, the Unknown, and the Believed specifically found in English to help readers appreciate how the Harry Potter dialogues analysed in this study were classified. A summary is also provided in Table 1. 
Table 1. Summary of evidential and epistemic markers of Known, Unknown and Believed.

\begin{tabular}{|c|c|c|c|}
\hline & Known & Unknown & Believed \\
\hline $\begin{array}{l}\text { Lexical } \\
\text { Markers }\end{array}$ & $\begin{array}{l}\text { Evidential verbs (I re- } \\
\text { member...) } \\
\text { Epistemic verbal expres- } \\
\text { sions (I have no doubt ...) } \\
\text { Epistemic adverbials } \\
(\text { surely...) }\end{array}$ & $\begin{array}{l}\text { Negative form of the } \\
\text { evidential verbs of } \\
\text { the Known (I don't } \\
\text { remember...) } \\
\text { Adjectives }\end{array}$ & $\begin{array}{l}\text { Epistemic verbs (I sup- } \\
\text { pose...) } \\
\text { Verbal epistemic expres- } \\
\text { sions (it is possible...) } \\
\text { Epistemic adjectives and } \\
\text { adverbials likely, perhaps... } \\
\text { Modal verbs }\end{array}$ \\
\hline $\begin{array}{l}\text { Morphosyntactic } \\
\text { Markers }\end{array}$ & $\begin{array}{l}\text { Clauses in the present, } \\
\text { past and future indicative } \\
\text { with no lexical evidential } \\
\text { or epistemic marker }\end{array}$ & $\begin{array}{l}\text { "Literal" interroga- } \\
\text { tives (i.e. excluding } \\
\text { rhetorical questions, } \\
\text { question tags, etc.) }\end{array}$ & $\begin{array}{l}\text { Modal verbs in conditional } \\
\text { and subjunctive moods } \\
\text { If clauses } \\
\text { Epistemic future }\end{array}$ \\
\hline
\end{tabular}

\subsubsection{Markers of the known}

There are three main groupings of lexical markers which signal Known information (certainty). The first of these groupings comprises evidential verbs, specifically in the present simple tense and primarily in the first person (singular or plural), e.g. I know, I remember, I see. Evidential verbs not found in the first person are those whose grammatical patterning requires them to be expressed in the third person (singular or plural) even if semantically they are perceived in the first person, e.g. it tastes like, they remind me. The second grouping of lexical markers of the Known are verbal expressions of certainty such as I am sure, I have no doubt, I am convinced. Related to these are epistemic adjectives and adverbs which explicitly express aspects of certainty, e.g. positive, undoubtedly, sure(ly), certain(ly).

As well as these classes of lexical markers the Known (certainty) is also normally communicated by clauses in the indicative mode (past, present or future), even when no lexical evidential or epistemic marker is present, e.g. Alex was on the beach yesterday, Alex will be on the beach tomorrow).

\subsubsection{Markers of the unknown}

The Unknown is communicated lexically through the negative form of those verbs which, if affirmative, signal the Known, e.g. I don't know, I don't remember, I don't see. Clearly in this sense, the function of the negative is to indicate absence of certainty, not to indicate uncertainty (Believed). The same can be said for adjectives, whether these be adjectives with negative prefixes, e.g. The cause of the technical fault is unknown, or adjectives whose copula verb is negated, e.g. The cause of the glitch is not known.

It is perhaps the morphosyntactic markers which mark out the Unknown most clearly, however. Literal interrogative sentences, i.e. those whose function is indeed interrogative and not merely rhetorical, can signal the Unknown because 
in asking a question the speaker/writer simultaneously signals that he or she does not possess a particular piece of information. Thus Where is Alex? implicitly communicates that the speaker does not know where Alex is.

\subsubsection{Markers of the believed}

The lexical markers which normally communicate the Believed (uncertainty) include epistemic verbs (I believe, I doubt, I imagine, I suppose, It seems) and other verbal epistemic expressions including it is probable/ possible, I am uncertain/ not certain, I am not sure, as well as related adjectives and adverbials adverbs (likely, possible, probably, perhaps). In addition to these clearly epistemic forms, modal verbs can also be indicators of the Believed, but in order to do so they must be expressing an epistemic meaning, e.g. can/could/must for their epistemic function denoting deduction or supposition, but not when they are being used in another of their functions (can/could for ability; or deontic must).

When used to indicate the conditional mood, modal verbs of all types are held to be morphosyntactic markers of the Believed, as are verbs found in the subjunctive. Related to this is the epistemicity inherent in conditional structures (if-clauses): conditional structures express Believed information in both the protasis and apodosis, with the exception of the 'zero conditional', in which "if" can be paraphrased by a temporal conjunction, which does not express uncertainty. Finally, the epistemic future, i.e. the conjectural use of the future which can be paraphrased by other Believed expressions, is also a marker of the Believed (uncertain).

\section{Harry Potter and KUB theory}

KUB Theory has potential applications in literary analysis, in particular as a means of investigating the resolution of Unknowns within plot development. By categorizing short sequences of text as Known, Unknown or Believed, it is possible to view the progression of events at an abstract level, without getting bogged down by the words, as it were. For this study, we chose to focus on the dialogic text (i.e., the direct speech) in one chapter of the final book of the series, Harry Potter and the Deathly Hallows. This final book is interesting for a number of reasons, both literary and linguistic; indeed Granger (2008) describes it as "the capstone and most intriguingly complex book of author J.K. Rowling's seven-book series" (2008, i). The choice was made to apply KUB theory to Hallows because a keyword analysis conducted in a previous study (Philip 2011) had identified in it a number of potential 'pivot points' which were not restricted to the single book, but rather affected the narrative thread of the entire seven-book epic. Chapter 10 was only one of several pivot points identified, but it is the first to concern plot rather than character 
development. In other words, some pivot points significantly alter the way in which a character is presented (e.g. Dumbledore in Chapter 2), which has repercussions for plot because his or her expected behaviour can no longer be taken for granted. Other pivot points introduce unexpected people, places and/or objects, which change the direction of the plot. Chapter 10 is one of these, and is important because several pivot features are present at the same time. The three main characters find themselves isolated from adult guidance for the first time (absence of expected characters). They are physically in a new location ( 13 Grimmauld Place, the house left to Harry by his deceased godfather) and make plot-related discoveries there. They also re-evaluate the persona of an existing character (the house elf, Kreacher), and are provided with new information which consolidates what they already knew or suspected and thus allows them to formulate their immediate course of action. This chapter marks the end of one episode in the narrative and sets up the conditions for a new one to begin. All this make it ideal for analysis using KUB Theory.

Part of the research team, therefore, hoped that by studying this particular section of the data, further confirmation of the chapter's role within the overall narrative would be confirmed; the others hoped that it would open up a new area of research in which to apply the theory under development.

\section{Data and methods}

The data examined in the present study is, as has already been mentioned, the direct speech uttered in Chapter 10 of Harry Potter and the Deathly Hallows. In order to prepare the data for preliminary classification and analysis, the direct speech was stripped out of the chapter to form a 'script.' The script was separated into speaker turns (100 in total) and these were entered into an Excel file along with information regarding the speaker's identity. An initial reading of the script led to the decision to subdivide it into five sections: the first of these will not be discussed here since it is not part of a dialogue proper (it is an isolated magical formula, "Lumos!", which Harry utters when he is alone), the remaining four were determined on the basis of the conversational content, and vary in length (dialogue 5 is longer than 2,3 , and 4 taken together).

\subsection{Tagging the data}

Each of the five members of the team were then left to classify ('tag') the data individually, using the three agreed tags, Known, Unknown, and Believed. This immediately led to the necessity to subdivide each turn, because it was found that information of more than one type was present and it was therefore impossible to 
assign only one tag to the utterances. The decision was taken to split the data in to clause-length chunks, i.e. into shorter pieces than had been used in previous applications of KUB theory by the team (who had operated at the level of proposition). These short chunks, it was agreed, could be merged again at a later stage if desired. However, there are advantages in using as fine-grained an analysis as possible: not only does it eliminate the need to repeat analysis at a later stage in order to locate details that were not considered in a first reading, it also makes it possible to observe the interaction and directionality of Known, Unknown and Believed information. In other words, rather than classifying an entire proposition as e.g. Known because the introducing verb is an evidential marker (I understand...), each clause within the proposition was tagged separately so that the information flow could be observed more clearly, e.g. $\mathrm{K} \rightarrow \mathrm{B}$ in I understand ${ }_{\mathrm{KNOWN}} \mid$ why you'd love to talk to her about your mum and dad, and Dumbledore, too ${ }_{\mathrm{BELIEVED}}$; or $\mathrm{B} \rightarrow \mathrm{K}$ in And I think BELIEVED $_{\text {I I nnow why }}$ KNOWN $_{\text {. }}$

Once all members of the team had completed their individual categorization, the results were compared and a definitive version of the analysis was produced (see the extract in Figure 2). On the whole, inter-rater agreement was very high, but the fine-grained analysis brought out some aspects which required further discussion. There were, in fact, several clauses which at least some of the team had been unable to classify, while in other cases there was a divergence of opinion regarding which tag to assign. Imperatives and question tags were the main source of disagreement here, because neither is truly epistemic: imperatives are directives, which traditionally belong to deontic modality, and yet within KUB they could arguably belong to Known, since the utterer knows what s/he wants. "Literal" questions, on the other hand, are Unknown as far as KUB theory is concerned; yet question tags are a little different: their function is not to provide information but to mitigate information presented in the preceding clause. It was agreed to classify imperatives, question tags, vocatives and also 'miratives' (DeLancey 1997)

\begin{tabular}{llll}
\hline Turn & Speaker & Text & Tag \\
\hline 27 & Harry & $\begin{array}{l}\text { Hermione. } \\
\text { Come back up here. }\end{array}$ & $\begin{array}{l}\text { vocative } \\
\text { imperative }\end{array}$ \\
& & What's the matter? & unknown \\
28 & Hermione & R.A.B. & known \\
29 & Harry & I think & believed \\
& & I've found him. & believed \\
& & In your mum's letter? & unknown \\
30 & Hermione & But I didn't see - & known \\
& & Sirius's brother? & unknown \\
\hline
\end{tabular}

Figure 2. Extract from classified data - Dialogue 3, turns 27-30 
separately, i.e. outside or not belonging to KUB, until such a time as they could be discussed in detail, and the disagreements resolved to the satisfaction of all.

\subsection{Analysis of the tagged data}

Once the KUB tags had been agreed, we went on to analyse the distribution of information types in the data. We were interested to discover the proportions of Known, Unknown and Believed information over the chapter's dialogues as a whole, and also (i) within each of the sections we had identified and (ii) in the speech of individual characters. In other words, we wanted to see if there was any noticeable shift in the type of information uttered from the start of the dialogic section (about mid-way through Chapter 10) to the end of the chapter, and to see if any of the dialogues could be characterised as Known, Unknown or Believed. We also wanted to investigate the types of information uttered by the three principal characters of the Harry Potter series - Harry himself and his friends, Ron and Hermione, as well as the house-elf Kreacher, who is a key character in the chapter under investigation - to ascertain to what extent their narrative roles are played out in the things they say as well as in the way they act.

\section{KUB distribution in Hallows Chapter 10}

To get an initial idea of how Known, Unknown and Believed clauses were distributed over the chapter, we prepared a modified version of the script file in simple text format so that we could process it in WordSmith Tools version 5 (Scott 2008) and obtain a graphic representation of occurrences of these types of data. To prepare this file, we preserved the direct speech and tags in the analysis file (cf. Figure 2) but formatted the tags for reading with the corpus analysis software. Figure 3 shows this presentation of the data, using the same extract from the text already seen in Figure 2.

Extracting the distributional plot for each of the Known, Unknown and Believed clauses made it possible to appreciate that Known is - in this data at least - a constant, while both Unknown and Believed clauses cluster together and also tend to appear in "bursts". This becomes more visible if the three separate plots are superimposed. Figure 4 shows the overall distribution of KUB clauses in

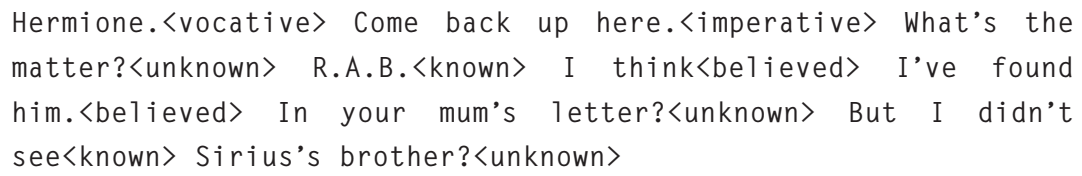

Figure 3. Tagged text prepared for corpus processing 


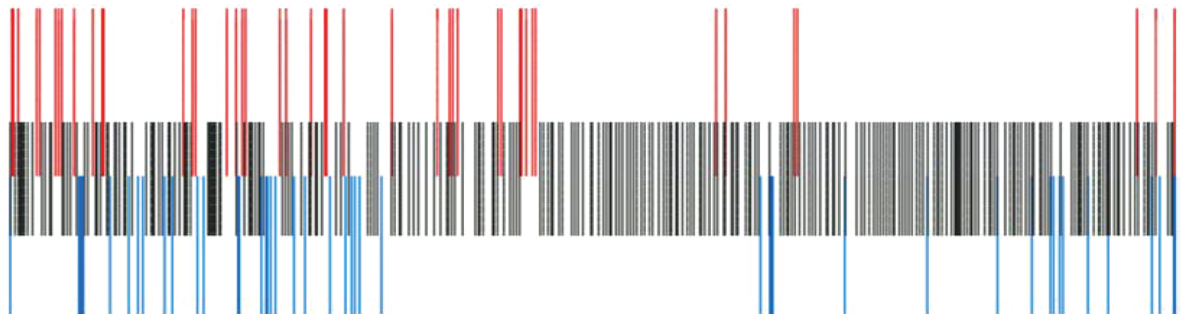

Figure 4. Distribution of KUB in Chapter 10

Chapter 10: Known clauses (in the middle line) are clearly constant throughout the chapter, while both Unknown (lines protruding upwards) and Believed (lines protruding downwards) can be seen to cluster - both individually (i.e. clusters of Unknown clauses) and together (clusters of Unknown and Believed clauses) but always interspersed with Known, the constant.

The graphic representation of the overall distribution of information types shows that at the start of the chapter's dialogic section Known, Unknown and Believed clauses are mixed in fairly even proportions. Believed clauses then peter out, as do Unknown clauses, and Known then dominates till the end of the chapter. There is a central Known-only section, after which Believed clauses start to creep in again. The end of the first block of Believed clauses marks the end of the fourth section of the dialogue; the fifth stretches over more than half of the direct speech data in the chapter, and is characterized by questions and (mainly) answers.

Figure 4 can be seen as an abstract summary of the chapter's content: at the start, Ron, Hermione and Harry are trying to solve a number of inter-related conundrums, and this involves questioning, answering and hypothesizing - or Unknown, Known and Believed clause types. The Known-only section (which continues until the end even though Believed and Unknown clauses do return to the scene) is a substantial "revelations" passage in which Kreacher tells what he knows, did and saw. The end of the chapter takes this new information as the basis for agreeing the next course of action to take, which requires some negotiation (questions being asked: Unknown) and supposition (Believed). There is, then, a distinct shift in information type over the course of the chapter, which parallels the change in direction of the narrative thread.

What this representation does not reveal, however, is information about who is conveying what type of information, i.e. how the author uses the characters' voices to present information of varying types (Known, Unknown, Believed) at particular points in her narrative. This is an additional area of interest, and especially so because the roles that the characters play in the narrative as a whole is a topic of interest for the literary analysis of these books. It has been observed (Granger 2007, 2008) that Harry has two close friends, not just one, and even more unusually for 
a boy hero, one of those friends is a bookish girl. These two friends play different roles in the unravelling of the plot and the action that takes place in the stories, and are necessary because Harry is no superhero - he is an orphan from a stigmatized "mixed-blood" family; his school grades are mediocre; he is neither rich nor powerful, nor even good-looking. His friends make up — at least in part - for these defects. Ron is Harry's action sidekick, a faithful companion in the classroom and on the sports field. Ron belongs to the magical world, and his direct speech is often used by the author to voice opinions or statements of fact about that world so that the reader finds out about this world through the characters' dialogue rather than through the narration. Hermione, on the other hand, is the brains of the trio. Studious and conscientious, it is she who masters spells and potions before the others and always makes the essential connections between fragments of information; these qualities make her in many respects a substitute for an adult companion, since she is more informed, reliable and competent than the boys are.

To what extent are these narrative roles reflected in the dialogic roles of the characters in this chapter? Firstly, we can observe that the number of clauses of each type uttered by each of the characters in the chapter does indeed reflect their narrative roles as already identified by literature scholars (e.g., Behr 2005, Dresang 2002). In fact, we would expect Hermione, the brainbox, to hypothesise and elaborate information more than the others, using Believed clauses. This she does, uttering $73 \%$ of the Believed clauses in the extract. Yet not only does Hermione utter more Believed clauses than the others do; when she pronounces a Believed clause, she also uses more words than the average for that clause type -7.8 words compared to the average of 7.3 - and significantly more words than her own personal average of 5.2.

Of course, Voldemort would have considered the ways of house-elves far beneath his notice, $_{\text {BELIEVED }} \mid$ just like all the pure-bloods who treat them like animals ${ }_{\text {KNOWN }} \mid \ldots$ it would never have occurred to him $_{\text {BELIEVED }} \mid$ that they might have magic $c_{\text {BELIEVED }} \mid$ that he didn't. BELIEVED $_{\text {. }}$

(Hermione, turn 79)

The same general pattern is repeated for the other characters. Harry is characterized in this extract by Unknown clauses - he is asking questions, seeking information that he can then act upon. Harry utters $53 \%$ of all the Unknown clauses in the extract and Harry's Unknown clauses are on average 4.9 words long, compared to an average of 4.5 for Unknown clauses in general. These clauses are shorter than the average (5.2 for Harry; 5.5 overall).

Harry: I've got a question for you, ${ }_{\mathrm{KNOWN}} \mid$ and I order you to answer it truthfully. IMPERATIVE Understand? UNKNOWN

Kreacher: Yes, Master. ${ }_{\text {KNOWN }}$ 
$\begin{array}{ll}\text { Harry: } & \text { Two years ago, there was a big gold locket in the drawing room } \\ & \text { upstairs. }{ }_{\text {KNOWN }} \mid \text { We threw it out. }{ }_{\text {KNOWN }} \mid \text { Did you steal it } \\ & \text { back? }{ }_{\text {UNKNOWN }} \\ \text { Kreacher: } & \text { Yes. }{ }_{\text {KNOWN }} \\ \text { Harry: } & \text { Where is it now? }{ }_{\text {UNKNOWN }} \\ \text { Kreacher: } \quad \text { Gone. }{ }_{\text {KNOWN }} \\ \text { Harry: } \quad \text { Gone? }_{\text {MIRATIVE }} \mid \text { What do you mean, }{ }_{\text {UNKNOWN }} \mid \text { it's gone? }{ }_{\text {UNKNOWN }}\end{array}$ (Harry and Kreacher, turns 55-61)

Ron's role in the books is principally as "action sidekick": and in this chapter he is responsible for only $4 \%$ of the words spoken, so it is clear that brains (Hermione), not brawn, are required at this stage. But what Ron does here through his speech is to make explicit information that has already emerged in a perhaps less direct form, or information regarding the magical world. He is therefore aiding the reader, not his companions. Ron's questions, for instance, are not aimed at discovering or uncovering information (unlike Harry's) but rather exploit his apparent cluelessness to ensure that the reader has understood what is going on:

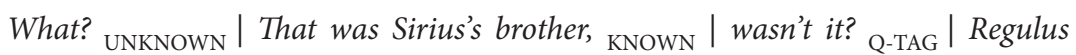
Arcturus ... Regulus ... R.A.B.! ${ }_{\text {KNOWN }} \mid$ The locket - you don't reckon -? ${ }_{\text {BELIEVED }}$

(Ron, turn 33)

And Ron's Known clauses provide filler-information - not information directly pertaining to events, but to their interpretation from the viewpoint of a wizard. His insights into the magical world alternate Known clauses with question tags as he states (what he believes to be) the obvious:

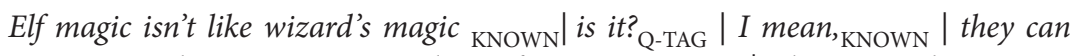
Apparate and Disapparate in and out of Hogwarts ${ }_{\mathrm{KNOWN}} \mid$ when we can't. ${ }_{\mathrm{KNOWN}}$

(Ron, turn 78)

Kreacher is a different order of character: he appears only sporadically in the books and is somewhat two-dimensional. He has no depth nor does he need any, because in the end his function is to supply information which allows the plot to continue. In the chapter under examination, he contributed only to our "Dialogue 5", i.e. the long dialogic passage which is dominated by Known clauses.

Although all four speakers in this chapter utter a high proportion of Known clauses - it has already been observed (Figure 4) that Known clauses are constant throughout the dialogic part of the chapter, and in fact they account for 274 (66\%) of the 415 clauses examined - Kreacher utters $40 \%$ of them, even though he only has 16 speaker turns. These turns all feature many clauses, however, each of which is also long in terms of the number of words used. So although Kreacher only has 16 turns, his speech accounts for $27 \%$ of the clauses in the chapter and $33 \%$ of the 
words uttered. Once he starts talking, the words flow out, and most of what he says (100 of 101 clauses) is Known. Kreacher's Known clauses are an average of 6.8 words in length, compared to an average of 5.9 for Known clauses overall.

Master Sirius ran away, good riddance, ${ }_{\mathrm{KNOWN}} \mid$ for he was a bad boy ${ }_{\mathrm{KNOWN}} \mid$ and broke my Mistress's heart with his lawless ways. ${ }_{\text {KNOWN }} \mid$ But Master Regulus had proper pride; ${ }_{\text {KNOWN }} \mid$ he knew ${ }_{\mathrm{KNOWN}} \mid$ what was due to the name of Black and the dignity of his pure blood. ${ }_{\text {KNOWN }}$ For years he talked of the Dark Lord, ${ }_{\mathrm{KNOWN}}$ | who was going to bring the wizards out of hiding to rule the Muggles and the Muggleborns.... KNOWN $\mid$ and when he was sixteen years old, ${ }_{\mathrm{KNOWN}} \mid$ Master Regulus joined

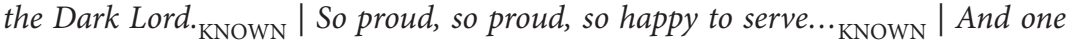
day, a year after he joined, ${ }_{\text {KNOWN }} \mid$ Master Regulus came down to the kitchen to see Kreacher. ${ }_{\text {KNOWN }} \mid$ Master Regulus always liked Kreacher ${ }_{\text {KNOwN }}$ | And Master

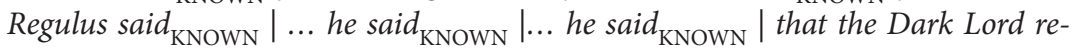
quired an elf. KNOWN

(Kreacher, turn 66)

Tables 1 and 2 list, respectively, the proportion of clause types uttered by each of the four characters in Chapter 10 and the average number of words uttered per clause type by the same characters.

\section{KUB theory in context}

In this section the data presented in Section 5 is subjected to analysis from a different viewpoint. Up to this point we have observed the characters who speak in Hallows Chapter 10, focusing on the types of information that characterize their

Table 1. Proportion of clause types uttered by speakers

\begin{tabular}{lclll}
\hline & Known & Unknown & Believed & Other \\
\hline Harry & $24 \%$ & $53 \%$ & $23 \%$ & $46 \%$ \\
Hermione & $31 \%$ & $33 \%$ & $73 \%$ & $46 \%$ \\
Ron & $5 \%$ & $14 \%$ & $2 \%$ & $7 \%$ \\
Kreacher & $40 \%$ & - & $2 \%$ & - \\
\hline
\end{tabular}

Table 2. Average number of words per clause type by speaker

\begin{tabular}{llllll}
\hline & Known & Unknown & Believed & Other & Average \\
\hline Harry & 5.9 & 5 & 6.4 & 3.1 & 5.2 \\
Hermione & 5.1 & 4.1 & 7.8 & 2.7 & 5.2 \\
Ron & 4.4 & 3.7 & 6 & 3.3 & 4.1 \\
Kreacher & 6.8 & - & 3 & - & 6.7 \\
AVERAGE & 5.9 & 4.5 & 7.3 & 2.9 & 5.5 \\
\hline
\end{tabular}




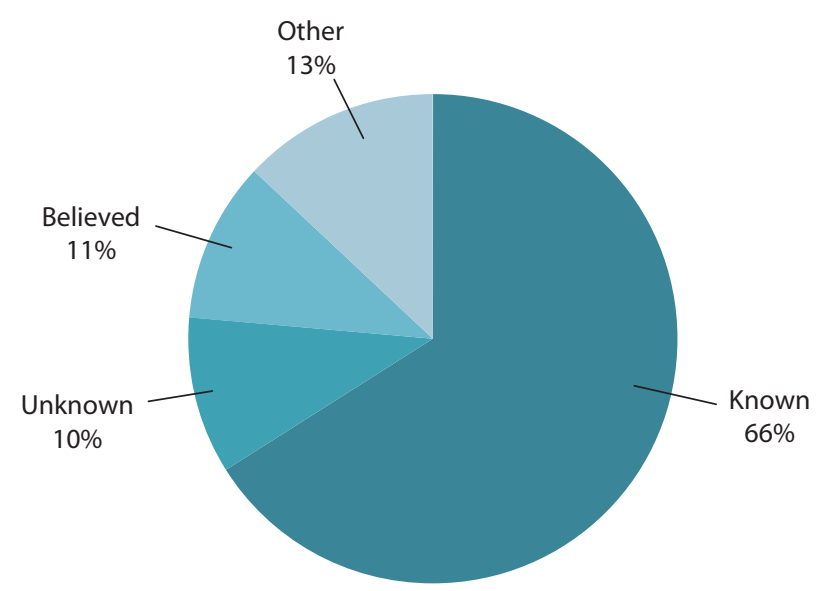

Figure 5. Proportions of Known, Unknown, and Believed clauses in Hallows Chapter 10

speech. Here, we take the information types as the starting point, look at their relative frequencies in the chapter, and how they are then distributed in text.

By way of introduction to this section, it is important to specify the proportions of each type of information. As can be seen in Figure 5, Known clauses account for $66 \%$ of the 415 clauses in the dialogic extract from the chapter under examination. Unknown and Believed clauses are very similar in frequency $(10 \%$ and $11 \%$ respectively), while 'Other' clauses (a mixture of vocatives, imperatives, question tags, etc.) total $13 \%$.

\subsection{The known in Harry Potter}

As is clear from the graphic representations in Figure 2, and Figure 5, Known clauses are a constant presence throughout the direct speech in Hallows Chapter 10; indeed they account for 274 of the 415 clauses uttered, or just over $70 \%$ of the running words. This clearly means that all characters must produce a considerable number of Known clauses, even though we have seen that Kreacher is the only one to use them to the virtual exclusion of other types and therefore to be 'characterisable' by Known information.

Figure 6 shows how Known clauses are distributed amongst the four speakers. Kreacher indeed has the lion's share at $40 \%$, despite the fact that he only utters $27 \%$ of all the clauses in the excerpt. The other three characters, in contrast, have a lower proportion of Known clauses compared to their overall clause output in Hallows Chapter 10. However, it is interesting to note that the percentages shown in Figure 6 roughly reflect the amount that each character speaks: Hermione utters $37 \%$ of all the clauses, more than Harry's 30\%, the same $7 \%$ difference also 


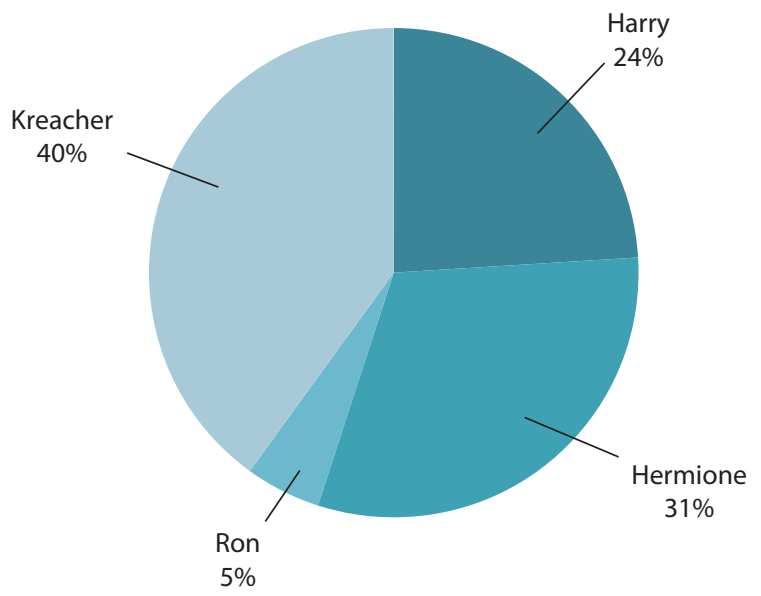

Figure 6. Proportion of Known clauses uttered by speakers

appearing in the proportions of Known clauses that each utters (31\% and $24 \%$ respectively). Harry in turn utters far more clauses than Ron (6\% of all clauses), this proportion again being reflected in the number of Ron's Known clauses.

Known clauses are in a sense unremarkable, since they pervade the dialogue from beginning to end. But they do not merely occur in sequence as in Kreacher's turns (cf. Section 5). One of the interesting things to note is how Known clauses combine with question tags or, as introducing verbs, with Believed information (as well as with other Known clauses).

I know ${ }_{\mathrm{KNOWN}} \mid$ what you're going to say, ${ }_{\mathrm{KNOWN}} \mid$ that Regulus changed his mind ... ${ }_{\text {KNOWN }} \mid$ but he doesn't seem to have explained that to Kreacher, ${ }_{\mathrm{BELIEVED}} \mid$ does he? ${ }_{\mathrm{Q}}$ TAG

(Hermione, turn 93)

In other words, the Known at the start of the turn shifts to Belief at the end, requiring agreement and support (in the form of the question tag). This kind of mitigation of the Known is still to be investigated in detail, although the example gives an insight into the further directions that the application of KUB theory to literary dialogue can take.

\subsection{The unknown in Harry Potter}

Unknown clauses tend to occur in bursts, as was mentioned in Section 5, and their distribution amongst the four speakers is far less predictable than is the case for Known clauses. Figure 7 makes this clear: Kreacher is absent (0\%) while Harry takes responsibility for over half (53\%), Hermione one third (33\%) and Ron 14\% 


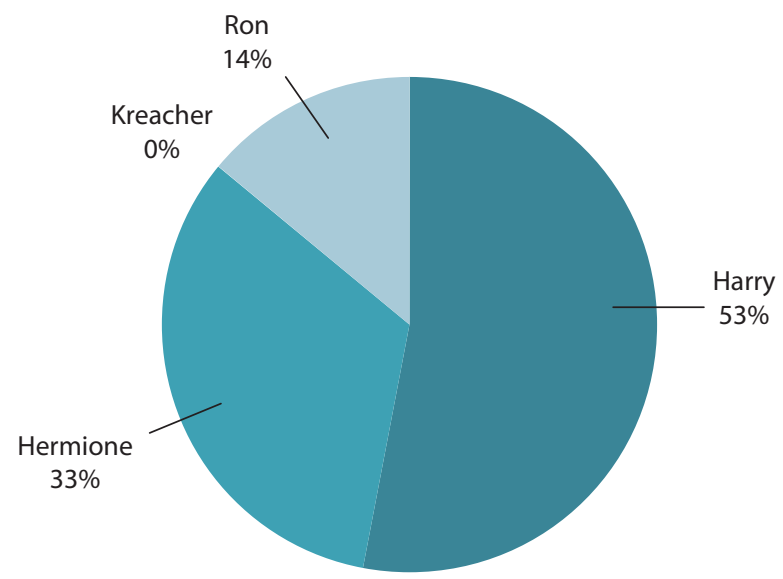

Figure 7. Proportion of Unknown clauses uttered by speakers

- highly significant when we remember that he utters only $6 \%$ of all clauses in the data examined.

Harry is the questioner in Hallows Chapter 10, but his questions are not always clear requests for information. The clusters of Unknowns often alternate with Known clauses and these can result in interesting dialogic effects, as in the following example, where Harry encourages Hermione to connect information she already knows (the name of the author of one of their school textbooks) with a new context - a friend of Harry's parents.

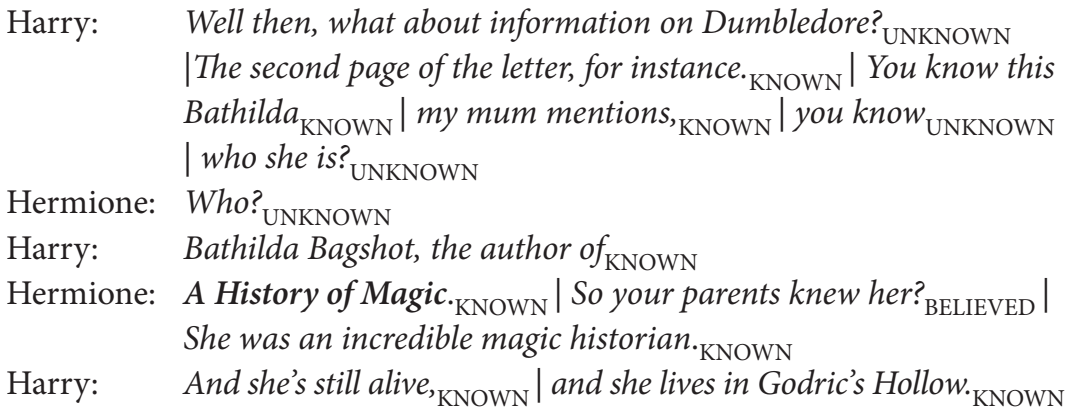
(Harry and Hermione, turns 15-19)

Here the interplay between Known and Unknown is especially interesting, since Harry is asking questions in order to share new information, turning the tables on Hermione for an instant, as she is usually the one of the trio who adds to the group's existing knowledge. But Harry also engages in more traditional questioning, in particular with Kreacher. In these sequences, the Unknowns combine with vocatives and imperatives which reflect the interaction between the two characters as master and servant, and are answered with Knowns: 
You called the locket "Master Regulus's" ${ }_{\text {KNOWN }} \mid$ Why? UNKNOWN $_{\text {. Where did it come }}$ from? UNKNOWN $\mid$ What did Regulus have to do with it? UNKNOWN $\mid$ Kreacher, ${ }_{\text {VOCATIVE }}$ | sit up IMPERATIVE $\mid$ and tell me IMPERATIVE $\mid$ everything you know about that locket, $_{\mathrm{UNKNOWN}} \mid$ and everything Regulus had to do with it! ${ }_{\mathrm{UNKNOWN}}$

(Harry, turn 67)

\subsection{The believed in Harry Potter}

Believed clauses amount to $11 \%$ of all the clauses in the data examined and, like Unknowns, often form clusters. Hermione is unambiguously the originator of the Believed information in Hallows Chapter 10, uttering $73 \%$ of these clauses, but Harry also has a fair share (23\%). Kreacher and Ron's contributions to the Believed, viewed globally, is negligible (2\% each): see Figure 8.

Clusters of Believed clauses tend to occur within a single speaker turn, although they also spill over from one speaker to another in consecutive turns. As can be seen from the example below, clustering clauses need not be consecutive, but they will occur in close proximity to one another, both preceded and followed by lengthy gaps where no similar clauses occur:

Harry: $\quad$ Ron's Auntie Muriel was talking about her at the wedding. ${ }_{\mathrm{KNOWN}}$ | She knew Dumbledore's family too. ${ }_{\text {KNOWN }} \mid$ Be pretty interesting to talk to, ${ }_{\mathrm{BELIEVED}} \mid$ wouldn't she? ${ }_{\mathrm{Q}-\mathrm{TAG}} \mid$

Hermione: I understand KNOWN $_{\mid} \mid$why you'd love to talk to her about your mum and dad, and Dumbledore, too. BELIEVED $\mid$ But that wouldn't really help us in our search for the Horcruxes, ${ }_{\text {BELIEVED }} \mid$ would it? ${ }_{\text {Q-TAG }}$

(Harry and Hermione, turns 19-20)

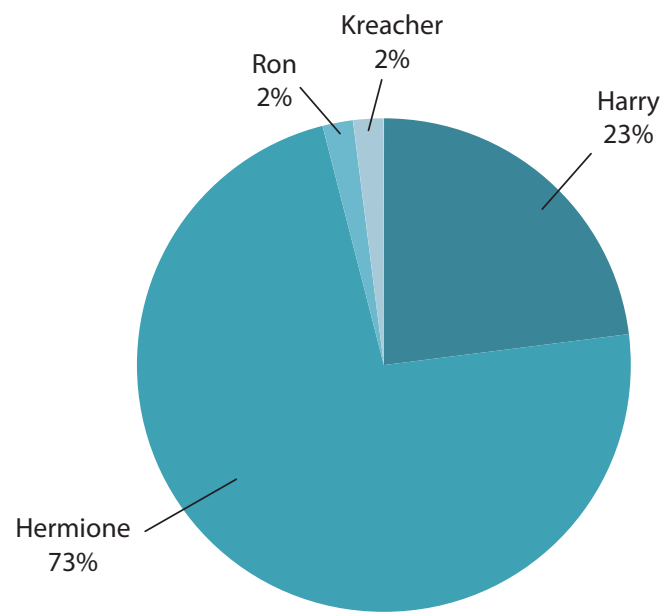

Figure 8. Proportion of Believed clauses uttered by speakers 
Introducing verbs can be found in Believed as well as in Known clauses. The example below shows consecutive Believed clauses following a Believed introducing clause, but it is not always necessary for this to be the case - Believed introducing clauses, although much less common than Known introducing clauses, can be followed by either Believed or Known but not, it seems - at least in the data analysed — Unknown (Philip et al. 2012).

$$
\text { But you'd think } k_{\mathrm{BELIEVED}} \mid \text { he'd already have all } \text { BELIEVED }_{\mid \text {he needed. }} \text { BELIEVED }_{\text {. }}
$$

(Hermione, turn 14)

Believed clauses occur in this dialogue at the start and at the end, and are absent from the central dialogue. Those which occur at the start serve to voice ideas and possibilities as the trio try to understand what is going on; those at the end, on the other hand, tend to take the form of suppositions as Kreacher is questioned about the past events he experienced. This shift in purpose of Believed information reflects the dynamics of the chapter's dialogue, which starts off with a situation of fragmented uncertainty and concludes with the formulation of the trio's imminent course of action.

\subsection{Other information types}

The other information types identified in the initial analysis and tagging of the data form three main groups - Vocatives, Imperatives, and Question tags, plus a ragbag of discourse markers and interactive strategies including Miratives (DeLancey 1997), false starts and exclamations. Attempts to 'force' these into the three KUB categories caused major disagreements between the members of the team, due to their varied and diverse linguistic backgrounds. Further investigation into these categories is underway.

\section{Conclusions}

7.1 What KUB theory tells us about Harry Potter

The application of KUB theory to this dialogic extract from Harry Potter and the Deathly Hallows has revealed interesting aspects of plot and characterization. In the first place, categorizing the clauses as Known, Unknown and Believed made it possible to generate an abstract schema of the plot development in Chapter 10. The graphic illustration of this abstraction (cf. Figure 4) demonstrates how the start of the dialogue is characterized by uncertainty in the broadest sense (i.e. interrogatives, absence of knowledge, reliance on belief and supposition over fact), 
and that this uncertainty is resolved, largely in Kreacher's extended turns, from the middle of the chapter onwards. The reappearance of Believed clauses in the final third of the script (equivalent to half-way through "Dialogue 5") indicates that the Known information imparted by Kreacher is being interpreted and elaborated by the other characters so that they are able to formulate their next course of action. In other words, KUB analysis reveals evidence of a problem-solution pattern (Hoey 2001) at work in this chapter, ${ }^{5}$ and it will be interesting to observe whether this is a feature that permeates the books as a whole or, perhaps, if it is a feature of pivot-points in the narrative. Clearly this requires further investigation using data from different parts of Deathly Hallows and, indeed, from the other books.

Another interesting aspect to emerge from this application of KUB Theory to Harry Potter is the way in which it confirms and lends weight to literary analyses of characterization. This, it should be added, has come as something of a surprise and was not at all amongst the key aims that the team had established at the start of the project. The discovery that Hermione is used by the author as a vehicle for Believed clauses may not in itself come as much of a revelation to those who are familiar with the books, but the quantitative evidence is important. It is all too easy to over-generalise the traits of the characters in a narrative, overlooking counterevidence which might undermine the strength of one's claims. Here we have significant figures: Hermione utters nearly three quarters of all the Believed clauses in the extract (cf. Table 1), and she also utters longer Believed clauses than any of the other characters (cf. Table 2). This tells us that she is using verbal reasoning hypothesis and conjecture - rather than making simple pronouncements about what she believes: compare

$$
\text { I think } k_{\text {BELIEVED }} \text { I've found him. BELIEVED }
$$

(Harry, turn 28)

with

Whether he'd manage to destroy it or not, ${ }_{\mathrm{BELIEVED}} \mid$ he'd want to keep it hidden from Voldemort, ${ }_{\text {BELIEVED }} \mid$ wouldn't he? ${ }_{\mathrm{Q}-\mathrm{TAG}}$

(Hermione, turn 46)

We therefore have confirmation that Hermione's dialogic role is as reasoned, and that her role in the narrative is not just the know-it-all bookworm but also - and fundamentally - the problem-solver (Behr 2005, Heilman and Donaldson 2009, Dresang 2002), i.e. not only does she know a lot, being studious and bookish, but she is also able to use and adapt that knowledge to overcome practical difficulties.

Of course, questions are the gateway to knowledge. Harry may not be much of an intellectual, but he does not shy away from asking questions. The information he gleans from the answers aids him in his quest to defeat Voldemort. Indeed the difference between Harry's Unknown clauses and Ron's in this extract is that Harry uses questions to obtain (and also to impart) knowledge, while Ron uses 
them phatically to consolidate friendship bonds. In this chapter, Ron also uses questions to communicate indirectly with the reader, ensuring that s/he has made all the relevant connections and can continue to follow the story.

\subsection{What Harry Potter tells us about KUB theory}

In this study, we refined the level of analysis to the clause rather than maintaining the previously-used level of proposition. This was partly in response to the different type of text being analysed - literary dialogue stripped out of a narrative, rather than transcribed speech - and partly because the purpose of the analysis was different. In previous studies, the primary aim had been to identify evidential and epistemic markers. Here, the purpose was to use these markers, under the umbrella of KUB theory, to analyse a text through a discovery-based approach; in doing so, we came across some clauses that were not (or were not easily) classifiable within the Theory of the Known, the Unknown, and the Believed. These 'anomalies' require more detailed consideration, which is why they have only been mentioned in passing here. We also noticed that within individual sentences, different types of information were often being presented in the constituent clauses. For instance, a proposition starting with a Known introducing verb might contain Believed information in the ensuing dependent clause. The interplay between information types within a single proposition, and within a single speaker turn, is another area which we are also investigating further. That said, the core of KUB Theory has allowed us to understand the information dynamics in a key episode in Deathly Hallows - and in the overarching Harry Potter narrative - providing empirical evidence which supports literary interpretations of characterisation and plot progression. While it would be overambitious to apply KUB analysis to the entire seven-book series, it will be worthwhile to select further episodes for scrutiny, to obtain a 'KUB-snapshot' of Harry Potter.

\section{Notes}

1. "'They're easy to underestimate because of what I call the three Deathly Hallows for academics, says James Thomas, a professor of English at Pepperdine University. 'They couldn't possibly be good because they're too recent, they're too popular, and they're too juvenile'” (Gibbs 2007).

2. The books were translated not only into a host of foreign languages but also into American English. On this not uncontroversial topic, see Gleick 2000, Nel 2002.

3. Granger $(2007,2008)$ puts forward a convincing argument for both friends being necessary, forming a trio with Harry which represents the mind (Hermione), body (Ron) and spirit (Harry); this is supported by J.K. Rowling's comments in various interviews (Granger 2007, 
121-122 and 2008, 26). Other authors recognise Ron as the best friend and Hermione as an 'accessory' who becomes more important and prominent as the series progresses (Pharr 2002, 62, Doughty 2002, Heilman and Donaldson 2009, 146).

4. On the repetitive nature of the plot progression, see Gupta (2009, 94-95 and ff.); on the 'Hero's quest' narrative, see Granger (2007, 118-129); for narrative structures in general, see Fenske (2008).

5. The problem-solution pattern is a basic textual pattern found especially in discursive text but also elsewhere, such as in the dialogue under examination in this study. In the pattern, a "problem" is proposed or raised, and it is then resolved in the ensuing text (sometimes followed by an "evaluation", again especially in discursive texts - see Hoey 2001). The pattern is often repeated within a single text, sometimes in the form of an overarching problem which is solved through the resolution of smaller "sub-problems". In the present dialogue, the most significant "problems" present at the start are: "Who is R.A.B?" and "What happened to the locket?", both of which are answered in considerable detail in the later parts of the dialogue.

\section{References}

Aikhenvald, Alexandra. 2003. "Evidentiality in typological perspective." In Studies in Evidentiality, ed. by Alexandra Aikhenvald, and Robert Malcolm Ward Dixon, 1-31. Amsterdam: John Benjamins.

Aikhenvald, Alexandra. 2004. Evidentiality. Oxford: Oxford University Press.

Behr, Kate. 2005. “'Same-as-difference': Narrative transformations and intersecting cultures in Harry Potter." Journal of Narrative Theory 35 (1): 112-132.

Billone, Amy. 2004. “The boy who lived: From Carroll's Alice and Barrie's Peter Pan to Rowling's Harry Potter." Children's Literature 32: 178-202.

Bongelli, Ramona, and Andrzej Zuczkowski. 2008. Indicatori Linguistici Percettivi e Cognitivi. Rome: Aracne.

Bongelli, Ramona, Carla Canestrari, Ilaria Riccioni, Andrzej Zuczkowski, Cinzia Buldorini, Riccardo Pietrobon, Alberto Lavelli, and Bernardo Magnini. 2012. "A corpus of scientific biomedical texts spanning over 168 years annotated for Uncertainty." In Proceedings of the Eight International Conference on Language Resources and Evaluation (LREC '12), ed. by Nicoletta Calzolari, Khalid Choukri, Thierry Declerck, Mehmet Uğur Doğan, Bente Maegaard, Joseph Mariani, Jan Odijk, and Stelios Piperidis, 2009-2014. European Language Resources Association (ELRA).

Bongelli, Ramona, Ilaria Riccioni, and Andrzej Zuczkowski. Forthcoming. Certain-Uncertain, True-False, Good-Evil in Italian Political Speeches.

Boye, Kasper. 2010. "Semantic maps and the identification of cross-linguistic generic categories: Evidentiality and its relation to epistemic modality." Linguistic Discovery 8 (1): 4-22.

Bronski, Michael. 2003. "Queering Harry Potter." Z magazine. September 2003. http://www.zcommunications.org/queering-harry-potter-by-michael-bronski. Accessed 5 September 2012.

Byatt, A.S. 2003. "Harry Potter and the childish adult." The New York Times. July 7, 2003. http://www.nytimes.com/2003/07/07/opinion/harry-potter-and-the-childish-adult.html. Accessed 5 September 2012. 
Chafe, Wallace. 1986. "Evidentiality in English conversation and academic writing." In Evidentiality. The Linguistic Coding of Epistemology, ed. by Wallace Chafe, and Johanna Nichols, 261-272. Norwood, NJ: Ablex Publishing Corp.

Cherland, Meredith. 2008. "Harry's girls: Harry Potter and the discourse of gender." Journal of Adolescent \& Adult Literacy 52 (4): 273-282.

Cornillie, Bert. 2007. Evidentiality and Epistemic Modality in Spanish (Semi-) Auxiliaries: A cognitive-functional approach. Berlin: Mouton de Gruyter.

De Haan, Ferdinand. 1999. "Evidentiality and epistemic modality: Setting boundaries." Southwest Journal of Linguistics 18 (1): 83-101.

DeLancey, Scott. 1997. "Mirativity: The grammatical marking of unexpected information." Linguistic Typology 1: 33-52.

Dendale, Patrick, and Liliane Tasmowski. 2001. "Introduction: Evidentiality and related notions." Journal of Pragmatics 33 (3): 349-357.

Doughty, Terri. 2002. "Locating Harry Potter in the "Boys' Book" market." In The Ivory Tower and Harry Potter: Perspectives on a literary phenomenon, ed. by Lana A. Whited, 243-257. Columbia and London: University of Missouri Press.

Dresang, Eliza T. 2002. "Hermione Granger and the heritage of gender." In The Ivory Tower and Harry Potter: Perspectives on a literary phenomenon, ed. by Lana Whited, 211-242. Columbia and London: University of Missouri Press.

Fenske, Claudia. 2008. Muggles, Monsters and Magicians: A literary analysis of the Harry Potter series. Frankfurt am Main: Peter Lang.

Fitneva, Stanka A. 2001. "Epistemic marking and reliability judgments: Evidence from Bulgarian." Journal of Pragmatics 33 (3): 401-420.

Gibbs, Nancy. 2007. “J.K. Rowling." Time. December 19, 2007. http://www.time.com/time/specials/2007/personoftheyear/article/0,28804,1690753_1695388_1695436,00.html. Accessed 5 September 2012.

Givón, Talmy. 1982. "Evidentiality and epistemic space." Studies in Language 6 (1): 23-49.

Glaubman, Jane (ed.). Forthcoming. Reconstructing Harry: "Harry Potter" fan fiction on the World Wide Web. Durham, NC: Duke Univ. Press.

Gleick, Peter H. 2000. "Harry Potter, minus a certain favour." The New York Times. July 10, 2000. http://www.nytimes.com/books/00/07/23/specials/rowling-gleick.html. Accessed 5 September 2012.

Goatly, Andrew. 2004. "Corpus linguistics, systemic functional grammar and literary meaning: A critical analysis of Harry Potter and the Philosopher's Stone." Ilha do Desterro 46, 115-154.

González, Montserrat. 2005. "An approach to Catalan evidentiality." Intercultural Pragmatics 2 (4): 515-540.

Granger, John. 2007. Unlocking Harry Potter: Five keys for the serious reader. Wayne (PN): Zossima.

Granger, John. 2008. The Deathly Hallows Lectures. Allentown (PA): Zossima.

Green, Lelia, and Carmen Guinery. 2004. Harry Potter and the fan fiction phenomenon. Media/Culture 7 (5). http://journal.media-culture.org.au/0411/14-green.php. Accessed 8 September 2012.

Gupta, Suman. 2009. Re-reading Harry Potter. $2^{\text {nd }}$ ed. Basingstoke: Palgrave MacMillan.

Heilman, Elizabeth E., and Trevor Donaldson. 2009. "From sexist to (sort-of) feminist: Representations of gender in the Harry Potter series." In Critical Perspectives on Harry Potter ( $2^{\text {nd }}$ ed.), ed. by Elizabeth E. Heilman, 139-161. New York and London: Routledge. 
Hensher, Philip. 2000. "Harry Potter, give me a break." The Independent, January 25, 2000. Cited in Westman 2011, p. 105.

Hoey, Michael. 2001. Textual Interaction: An introduction to written discourse analysis. London: Routledge.

Ifantidou, Elly. 2001. Evidentials and Relevance. Amsterdam: John Benjamins.

Kamio, Akio. 1994. "The theory of territory of information: The case of Japanese." Journal of Pragmatics 21 (1): 67-100.

Kamio, Akio. 1997. Territory of Information. Amsterdam: John Benjamins.

Kidd, Kenneth. 2008. "Introduction: Outing Dumbledore." Children's Literature Association Quarterly 33 (2): 186-187.

Mushin, Ilana. 2001. Evidentiality and Epistemological Stance. Amsterdam: John Benjamins.

Nel, Philip. 2002. "You Say 'Jelly', I Say 'Jell-O'? Harry Potter and the transfiguration of language." In The Ivory Tower and Harry Potter: Perspectives on a literary phenomenon, ed. by Lana A. Whited, 261-284. Columbia and London: University of Missouri Press.

Nuyts, Jan. 2001. Epistemic Modality, Language and Conceptualization. Amsterdam: John Benjamins.

Nylund, David. 2007. "Reading Harry Potter: Popular culture, queer theory and the fashioning of youth identity." Journal of Systemic Therapies 26 (2): 13-24.

Palmer, Frank R. 1986. Mood and Modality. Cambridge: Cambridge University Press.

Papafragou, Anna. 2000. Modality: Issues in the semantics-pragmatics interface. Oxford: Elsevier Science.

Pennington, John. 2002. "From Elfland to Hogwarts, or the aesthetic trouble with Harry Potter." The Lion and the Unicorn 26, 78-97.

Petöfi, János Sándor. 1973. “Towards an empirically motivated grammar theory of verbal texts." In Studies in Text Grammar, ed. by János Sándor Petöfi, and Hannes Rieser, 205-275. Dordrecht: Reidel.

Petöfi, János Sándor. 2004. Scrittura e interpretazione: Introduzione alla testologia semiotica dei testi verbali. Rome: Carocci.

Pharr, Mary. 2002. "In medias res. Harry Potter as hero-in-progress." In The Ivory Tower and Harry Potter: Perspectives on a literary phenomenon, ed. by Lana A. Whited, 53-66. Columbia and London: University of Missouri Press.

Philip, Gill, Ramona Bongelli, Carla Canestrari, Ilaria Riccioni, and Andrzej Zuczkowski. 2012. "Introducing, reinforcing and mitigating known, unknown and believed in Harry Potter and the Deathly Hallows." Paper read at The Communication of Certainty and Uncertainty: Linguistic, Psychological, Philosophical aspects. Macerata, Italy, 3-5 October 2012.

Philip, Gill. 2010. “'You have your mother's eyes': Collocational resonance and symbolism in Harry Potter". Paper read at RaAm8 Researching and Applying Metaphor. Amsterdam, 30 June-3 July 2010.

Philip, Gill. 2011. "Key words, pivotal words and leading words in Harry Potter." Paper read at Corpus Linguistics 2011. Birmingham, UK, 20-22 July 2011.

Plungian, Vladimir A. 2001. "The place of evidentiality within the universal grammatical space." Journal of Pragmatics 33 (3): 349-357.

Rémi, Cornelia. 2012. Harry Potter Bibliography. http://www.eulenfeder.de/hpliteratur.html. Accessed 5 September 2012.

Riccioni, Ilaria, Ramona Bongelli, and Andrzej Zuczkowski. Forthcoming. The Communication of Certainty and Uncertainty in Italian Political Media Discourses. 
Safire, William. 2000. “Besotted with Potter." The New York Times. January 27, 2000. http://www. nytimes.com/library/opinion/safire/012700safi.html. Accessed 5 September 2012.

Sanders, José, and Wilbert Spooren. 1996. "Subjectivity and certainty in epistemic modality: A study of Dutch epistemic modifiers." Cognitive Linguistics 7 (3): 241-264.

Scott, Mike. 2008. WordSmith Tools Version 5. Liverpool: Lexical Analysis Software.

Tosenberger, Catherine. 2008a. "Homosexuality at the online Hogwarts: Harry Potter sash fanfiction." Children's Literature 36: 185-207.

Tosenberger, Catherine. 2008b. “'Oh my God, the fanfiction!': Dumbledore's outing and the online Harry Potter fndom”. Children's Literature Association Quarterly 33 (2): 200-206.

Van Der Auwera, Johan, and Vladimir A. Plungian. 1998. “Modality's semantic map." Linguistic Typology 2 (1): 79-124.

Westman, Karin E. 2011. "Blending genres and crossing audiences: Harry Potter and the future of literary fiction." In The Oxford Handbook of Children's Literature, ed. by Julia L. Mickenberg, and Lynne Vallone, 93-112. Oxford: Oxford University Press.

Willett, Thomas. 1988. "A cross-linguistic survey of the grammaticalization of evidentiality." Studies in Language 12 (1): 51-97.

Zuczkowski, Andrzej, Ramona Bongelli, and Ilaria Riccioni. 2011. "Proposizione costitutiva di mondo e indicatori linguistici percettivi e cognitivi nella lingua italiana." In Dimensionen der Analyse von Texten und Diskursen. Festschrift für János Sándor Petöfi zum achtzigsten Geburstag. Dimensioni dell'analisi di testi e discorsi. Festschrift für János Sándor Petöfi in occasione del suo ottantesimo compleanno, ed. by Klaus Hölkerm, and Carla Marello, 41-61. Berlin: Lit.

\section{Corresponding author's address}

Gill Philip

Department of Education, Cultural Heritage and Tourism

University of Macerata

Piazzale L. Bertelli

Contrada Vallebona

62100 Macerata

ITALY

gill.philip@unimc.it

\section{About the authors}

Gill Philip is a researcher in English language and translation at the University of Macerata, Italy, where she teaches English language and TEFL. A corpus linguist by training, she has published widely on various aspects of phraseology, figurative language and metaphor. Recent publications include Idioms (Routledge Linguistics Encyclopedia, 2010), Colouring Meaning (Benjamins, 2011) and Technology and Phrases (The Encyclopedia of Applied Linguistics, Wiley-Blackwell 2012). http://docenti.unimc.it/docenti/gillian-susan-philip

Ramona Bongelli is a researcher in General Psychology at the University of Macerata, Italy, where she teaches Psychology of Communication. Her main objects of research concern the study of verbal communication, both oral (everyday talk and political discourses) and written 
(scientific and literary texts). In particular, she is interested in the analysis of the linguistic forms used by speakers/writers to convey epistemic and evidential standpoints.

http://docenti.unimc.it/docenti/ramona-bongelli

Carla Canestrari is researcher in General Psychology at the University of Macerata, Italy, where she teaches General Psychology. Her main research interests concern: everyday and humorous conversations, cognitive mechanisms involved in the understanding of humorous texts, epistemic and linguistically-expressed cognitive states of mind.

http://docenti.unimc.it/docenti/carla-canestrari

Ilaria Riccioni is a researcher in General Psychology at the University of Macerata, Italy, where she teaches Psychology of Communication. Her scientific interests are focused on pragma-linguistic analysis of verbal interaction. In particular she is interested in relational dimensions of talk in interaction (main topics: discourse attuning, conflict, agreement-disagreement, troubles talk, advice giving), discourse and conversation analysis, politeness, political discourse and communication, intrapersonal communication, evidentiality and epistemicity, scientific writing. http://docenti.unimc.it/docenti/ilaria-riccioni

Andrzej Zuczkowski is Full Professor of General Psychology at the University of Macerata, Italy, where he is Director of the Research Centre for Psychology of Communication and the $\mathrm{PhD}$ programme in Psychology of Communication and Cognitive Processes. He was trained in Gestalt psychology, linguistics and Transactional Analysis psychotherapy. His main research topics concern the relationships between linguistic communication and perceptive/cognitive processes. http://docenti.unimc.it/docenti/andrzej-zuczkowski 